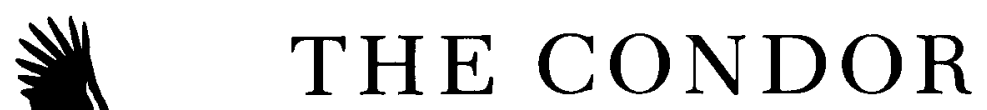

JOURNAL OF THE COOPER ORNITHOLOGICAL SOCIETY

\title{
SOCIAL ORGANIZATION OF THE BAND-TAILED MANAKIN (PIPRA FASCIICAUDA)
}

\section{MARK B. ROBBINS}

\begin{abstract}
I studied the social organization of the Band-tailed Manakin (Pipra fasciicauda) for 6.5 months in 1980 in undisturbed, lowland rain forest of southeastern Peru. Dominant males maintained closely-packed territories at localized sites in seasonally flooded forest. Within each territory, an alpha male, usually a beta male, and occasionally one or more non-territorial adult males performed complex, coordinated displays for attracting and exciting females. Alpha males were extremely sedentary, spending almost the entire day on territory. Beta males were less sedentary and visited with other alpha males at the lek. Alpha males encouraged all visiting conspecifics, except contiguous territorial owners, to join them in display. Territorial males showed no interspecific territoriality, except toward other lekking piprids. Once a female was attracted to a territory, only the alpha male actively courted her, while the subordinate male(s) observed from the adjacent vegetation. All disruptions of an alpha male courting a female were by subordinates associated with the territory. Beta males occupied the dominant position in both instances where there was a change in territorial ownership. Two types of acquisition of the alpha position were involved: (1) an alpha male was displaced by the beta male; and, (2) a beta male inherited ownership when the alpha male disappeared.
\end{abstract}

The neotropical family Pipridae displays nearly the full range of avian mating systems. Most manakins, particularly members of the genera Manacus, Chiroxiphia, and Pipra (Snow 1963, Sick 1967), are highly promiscuous. Males congregate at traditional sites in the forest, where they exhibit complex, ritualized displays to attract and excite females. Typically, each male displays solitarily, while maintaining an exclusive territory within the congregation or lek. In contrast, two or more males of the genus Chiroxiphia display together at exploded leks, i.e., male display sites are not tightly packed together (Slud 1957, Gilliard 1959, Foster 1977, 1981). This highly coordinated display among males was thought to be restricted only to members of Chiroxiphia. Recently, Schwartz and Snow (1978) and Robbins (1983) established that males of the Pipra aureola superspecies complex - the Crimsonhooded ( $P$. aureola), Band-tailed ( $P$. fasciicau$d a$ ), and Wire-tailed ( $P$. filicauda) manakinsalso exhibit true communal display. Elucidation of the social organization of these communally displaying species may offer clues about the evolution of this relatively rare type of mating system. The results of my 6.5-month study of the male-male interactions of the Band-tailed Manakin are presented here.

\section{STUDY AREA AND METHODS}

My study was conducted in the Tambopata Natural Wildlife Reserve, near the mouth of the Rio La Torre (=Rio D'Orbigny) on the south bank of the Rio Tambopata, in the Department of Madre de Dios, Peru (12 ${ }^{\circ} 50-55^{\prime} \mathrm{S}$ and $69^{\circ} 17^{\prime} \mathrm{W}$ ) from early June to mid-December, 1980 . The study site was in undisturbed, lowland rain forest at about $260 \mathrm{~m}$ elevation. Puerto Maldonado, ca. $25 \mathrm{~km}$ north-northeast of the study site, averages $1,897 \mathrm{~mm}$ of rain annually (Oficina Nacional de Evaluacion de Recursos Naturales 1976).

I visited five leks in seasonally flooded forest. Detailed observations were limited to a single lek composed of 10 territories. I monitored this lek almost daily from ground level blinds 10-25 $\mathrm{m}$ from the main display perches. Data collected at each territory included when and for how long males were present, the type 
and number of displays, and all general behavior, e.g., foraging, preening, clearing of territory, etc. Initially, observations were concentrated at seven clustered territories of the main observation lek; however, one of the territories was destroyed by a felled tree in late August.

Once the functions of the calls and displays were determined, I moved every fifth day from territory to territory. Occasionally, observation periods were modified to adjust for unusual events at a particular territory or for inclement weather. Observations were made primarily from first light (ca. 05:30) until display activity significantly decreased in the morning (ca. 08:00), and from early afternoon until most display activity ceased in the afternoon (ca. 15:30). Mid-morning and late afternoon observations were made periodically (total of $68 \mathrm{~h}$ ) to check on activity levels at those times.

During the first three weeks of the study, approximately 50 individuals (including all territorial owners) were mist-netted and colorbanded (celluloid leg bands). (See Robbins 1983 for a more detailed description of the study area and methods.)

\section{DEFINITION OF SOCIAL STATUS}

Alpha, beta, and non-territorial (visitor) rank refer to males in definitive plumage. Immature status refers to all males in non-definitive plumage. These categories do not denote the physiological breeding state of the birds, because I do not have data on gonadal development in this species.

Alpha male. An alpha male is the territorial owner; he dominates and usually initiates displays with all other males. He displays to a visiting female, and is present on territory for almost the entire daylight period.

Beta male. A beta male is subordinate to the alpha male, but dominant to other males (visitors). $\mathrm{He}$ is the principal displayer with the alpha male, and is usually present during the peak display periods.

Non-territorial (visitor) male. A non-territorial male is subordinate to both alpha and beta males. He may visit several territories in a single day or may go unrecorded at the lek for days or even months.

Immature. An immature is any male in nondefinitive plumage. These are non-territorial males that are primarily observers or that perform incomplete, uncoordinated displays.

\section{DISPLAY BEHAVIOR OF MALE}

PIPRA FASCIICAUDA

Robbins (1983) described the display repertoire of $P$. fasciicauda using the terminology of Schwartz and Snow (1978), where the calls and displays are clearly homologous with those of $P$. filicauda. Below, I summarize some of the components of the display of $P$. fasciicauda that are relevant to the interpretation of this study's data.

Appeasement whistle. An Appeasement Whistle is a soft, whistled, single note that is gradually inflected upward. This vocalization conveys a passive or non-aggressive state of the caller.

Display call. The Display Call is an abrupt call associated with encouraging a bird to display, in three types. The "normal" type is given by an alpha male when a visiting bird waits to come to the main perch to display. A visiting male may give this call, however, in the interval between the alpha male's departure from the main perch and his return with a Swoopin Flight. The second pattern, the Partial Display Call, is given by an alpha male when a visiting bird fails to join him in display. On these occasions, the owner flies to the same perch or to one adjacent to the non-cooperative bird and gives the call until the visitor either joins him in display or leaves the territory. The third type, the Slurred Display Call, is usually given by an alpha male when no other bird is present in the display area.

Culminating call. This vocalization is given only during a Swoop-in Flight. A male that is performing the Swoop-in Flight delivers the call the instant before he reaches the main perch.

Klok. The Klok is a low-intensity sound, apparently produced by the wings and given the instant before or upon landing on a perch.

Kloop. The Kloop is another mechanically produced sound, given at the lowest point of a Swoop-in Flight the instant before a male quickly ascends to the main perch. Both the Klok and the Kloop accent the conspicuousness of the male.

Side-to-side display. The Side-to-Side Display is performed by a male that is oriented perpendicular to a perch and makes several short hops to one side, then back to the original position. It is primarily performed by an alpha male on the main perch, and serves as an invitation to a visiting bird to join the performer on the main perch.

Short flight. The Short Flight is one in which a male flies with a normal flight pattern from one perch to another, in a more or less horizontal plane, and the instant before or upon landing, he produces a Klok. A male usually performs this display as soon as he detects the arrival of another bird in the display area.

Stationary display. In the Stationary Display, the body is held nearly horizontal, while 
TABLE 1. Percent of time males were present at territory $2 .^{\mathrm{a}}$

\begin{tabular}{|c|c|c|c|c|c|c|c|c|}
\hline Period & $\begin{array}{l}\text { Min. } \\
\text { observ. }\end{array}$ & WB & BKR & BY & AY & AA & YB & BW \\
\hline Julyb & 1,333 & 98.2 & 48.6 & 43.6 & 62.9 & 36.6 & 0 & 4.6 \\
\hline Julyc & 509 & 100.0 & 92.9 & 0 & 0 & 100.0 & 91.1 & 10.0 \\
\hline Aug. & 519 & 100.0 & 96.1 & 13.4 & 0 & 98.4 & 63.0 & 0 \\
\hline Sept. & 509 & 99.0 & 93.7 & 0 & 0 & 0 & 0 & 1.9 \\
\hline Oct. & 452 & 9.7 & 100.0 & 0 & 100.0 & 0 & 0 & 0 \\
\hline Nov. & 639 & 29.2 & 100.0 & 0 & 61.8 & 0 & 0 & 0 \\
\hline
\end{tabular}

Morning period only

2-18 July observation period.

26-30 July observation period.

the wings are slightly lowered and quivered. This display is exhibited when a male is anticipating the actions of another bird.

Flutter. The Flutter is the copulatory position of a male, in which he appears to be falling backward off a perch, with the wings spread and rapidly beating, while the head and upper body are slightly tilted forward.

Swoop-in flight. For the Swoop-in Flight, a male flies from the main perch to a perch 15$30 \mathrm{~m}$ away. Upon landing, he usually produces a $K l o k$; he then immediately turns around and quickly swoops downward, whence he produces Kloop at the lowest point of the swoop before swinging upward to the main perch. The Culminating Call is given the instant before he reaches the main perch. When the male reaches the main perch, he quickly turns around in mid-air, then lands on the perch facing in the direction from which he came.

The mechanics of intermale display are much the same as in solo display, except that, as the active male approaches the main perch, during the return part of the Swoop-in Flight, the passive bird usually bends forward and flies to an adjacent perch before he initiates a Swoop-in Flight. Display between an alpha male and his partner may be highly-synchronized and may continue for several minutes.

\section{RESULTS}

\section{SOCIAL ORGANIZATION}

Male status at the lek. With increasing age, males apparently progress through a sequence of social ranks at the lek. Immature males, which showed no adult male plumage characters, attempted displays with the territorial owner in $43 \%$ of the observations ( $n=37$ visits). These female-like plumaged males gave only weak, imperfect calls and were mainly observers, even though the owner attempted to entice them to the main perch. Immature males in more advanced plumage, with various amounts of red, black, and yellow plumage of the adult, joined the resident male in display in $63 \%$ of the observations $(n=29$ vis- its), although this rate of display was not significantly different from the more female-like plumaged group of males $\left(\chi^{2}=2.3, \mathrm{df}=1\right.$, $P>0.05$ ). The only displays that immatures (includes both groups) were seen performing were the Swoop-in Flight, the Side-to-Side, and the Flutter, and virtually none of these was perfected. I never heard an immature giving the Slurred Display Call or the Klok $(n=66$ visits). Since immatures are capable of giving the Kloop, however, they probably can produce the Klok. Some displays may not be incorporated into an individual's repertoire until after he molts into adult plumage and becomes established at a territory with an experienced male. The paucity of complete specimen data precludes a detailed analysis of plumage sequences in this species. Nonetheless, three males banded in immature plumage (no hint of adult male plumage) were in full adult dress within two years.

Males in adult plumage go through three stages (non-territorial, beta, and alpha), apparently related to age and experience. Like immature males, non-territorial adult males visit various territories and compete with owners and other visiting males. The amount of time a non-resident male spent in a territory was highly variable. Seven adult males were seen on only one or two occasions at the lek. All of their visits were brief $(<10 \mathrm{~min}$ per visit). In contrast, visitor $B G$ (initials refer to color combinations of bands) spent $31.2 \%(n=$ $563 \mathrm{~min}$ of observation time) of the August morning period at territory 5 (hereafter T5; see Table 1 for length of time of visitors at T2). If a visitor was overly aggressive, either the owner or a preferred partner chased him from the display area. For example, alpha and beta males, WB and BKR, of T2 chased visitor AA at least 15 times during the July morning periods ( $n=15$ days, 997 min with AA present).

Subordinate males competed intensely for the beta position; often the resident male either sat quietly or maintained a Stationary Display while two or more birds chased each other. For example, during July at T2 (ca. 1,860 min 
TABLE 2. Percent of time beta males spent on territory during early morning and afternoon periods.

\begin{tabular}{|c|c|c|c|c|c|c|c|}
\hline \multirow[b]{3}{*}{ Territory } & \multirow[b]{3}{*}{ Beta 8} & \multicolumn{3}{|c|}{ Morning } & \multicolumn{3}{|c|}{ Afternoon } \\
\hline & & \multicolumn{3}{|c|}{ Min. } & \multicolumn{3}{|c|}{ Min. } \\
\hline & & Present & Total & $\%$ & Present & Total & $\%$ \\
\hline 1 & BA & 1,903 & 3,248 & 58.5 & 369 & 1,547 & 23.8 \\
\hline 2 & AY & 847 & 1,091 & 77.6 & 297 & 663 & 44.7 \\
\hline 4 & YB & 942 & 2,230 & 42.2 & 99 & 1,263 & 7.8 \\
\hline 5 & RW & 370 & 563 & 65.7 & - & - & - \\
\hline 5 & BG & 1,309 & 2,055 & 63.6 & 438 & 1,126 & 38.8 \\
\hline
\end{tabular}

of morning observation time), the alpha male watched as one male pursued another on at least 12 occasions ( $<1 \%$ of observation time). The most extreme example of conflict between beta and non-resident males was recorded at this same territory in November, when I watched the alpha male as the beta male chased a visitor for ca. $33 \%(n=152$ min of observation time) of one morning's observation.

Males that gained beta status spent less time visiting other displaying males and spent more time in "their" display area. For example, as a visitor at $T 5, B G$ spent significantly less time as a visitor $(31.2 \%$ of $563 \mathrm{~min}$ observation time) than as a beta male $(63.6 \%$ of $2,055 \mathrm{~min}$ observation time; $\chi^{2}=188.4, \mathrm{df}=1, P<$ $0.001)$. After YB became established as a beta male at T4, I never saw him visiting T2 again, although he spent $91 \%(n=509 \mathrm{~min}$ of observation time $)$ and $63 \%(n=519 \mathrm{~min}$ of observation time) of his time visiting $\mathrm{T} 2$ in late July and August, respectively. Despite this trend, beta males visited and displayed with other territorial males at the lek. After morning display periods, beta males were often absent for prolonged periods during the remainder of the day (see Table 2). In T1, the same beta male displayed daily with the owner throughout the study. I rarely saw any overt aggression between the owner and beta male in such partnerships. For example, in over $80 \mathrm{~h}$ of observation time at $\mathrm{T} 1$, I saw the alpha and beta males fight on only two occasions. Nonetheless, there was constant, non-contact competition for mates between the two, with the beta male occasionally performing a Side-to-Side Display on the main perch when a femaleplumaged bird appeared. Alpha males were disrupted (scored as such when an alpha male chased a subordinate male during a female visit) during courtship of a female by subordinate males (beta and non-territorial males) $19.6 \%$ of the time $(n=51$ female visits when more than one male was present in a territory).

During the main observation periods (morning and afternoon), alpha males were present virtually the entire time. Even during non-peak periods (08:30-14:00; after 16:00), alpha males were almost always present $(n=$
$68 \mathrm{~h}$ of observation time). Exceptions included the following: alpha males BKR (T2) and BW (T4) were absent the beginning of one morning for 23 and $32 \mathrm{~min}$, respectively. Territory 5 was unoccupied for 92 min one afternoon by $\mathrm{RB}$. Except for these cases, I never noticed that an alpha male was absent during visits by other manakins.

Intraspecific territoriality. Except under unusual conditions (see summary of T4 in Chronology section), territorial owners did not tolerate the presence of owners of adjacent territories in their display areas. All other individuals, including the beta males of adjacent territories, were encouraged (with Side-to-Side Displays) to join the resident male in display. This implies that there was individual recognition between contiguous owners. There appeared to be a narrow neutral zone between adjacent territories where residents met. At the borders of $\mathrm{T} 2, \mathrm{~T} 3$, and $\mathrm{T} 4$, confrontations between owners usually $(68 \%, n=25$ encounters) involved nothing more than one or both birds exhibiting a Stationary Display or Short Flights for several seconds before each bird returned to the main display area of his respective territory. Fighting or chasing erupted occasionally $(32 \%)$, however, with both birds engaging in the zone for a few seconds. The dense vegetation made it difficult to determine the outcome of these encounters. As mentioned above, all other individuals were tolerated as long as they joined the resident male in display.

Interspecific territoriality. Resident males rarely defended their territories against birds of other species, even when mixed-species flocks visited a fruiting tree in an owner's display area. The resident male usually sat quietly in his territory while a flock moved through, although if he mistook one of its members for a conspecific, he moved to the main perch and performed a Side-to-Side Display. Even individual visits by a variety of species ( $n=22$ visits), ranging in size from the 8-g Whiteflanked Antwren (Myrmotherula axillaris) to the 50-g White-necked Thrush (Turdus albicollis), failed to elicit a response from the owner. On several occasions, birds of various 


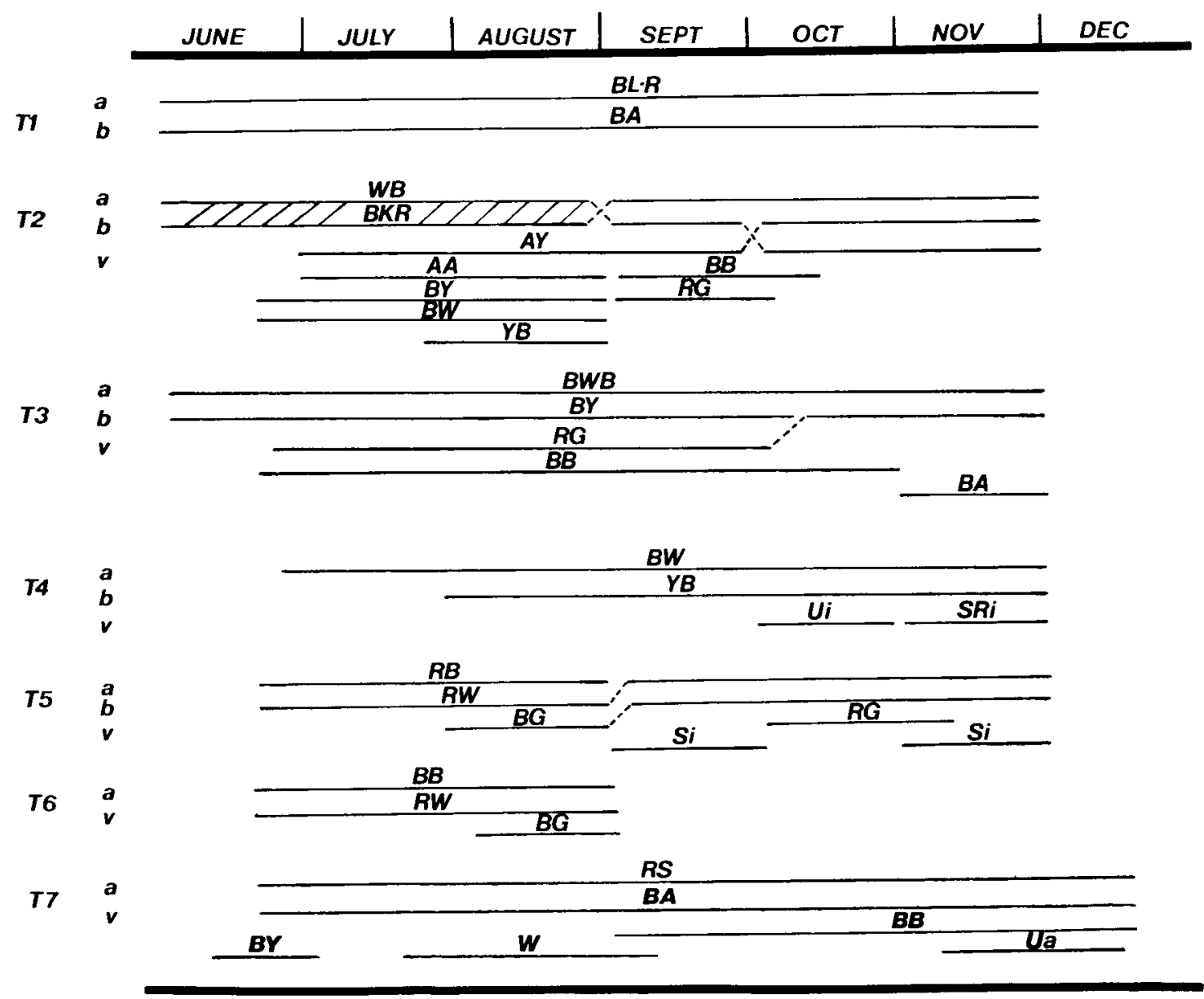

FIGURE 1. Chronology of territorial ownership at the lek. Alpha (a), beta (b), and non-territorial, i.e., visitor (v), males are listed for each territory. There was no beta male in T6 and T7. A dashed line indicates change in status by a male at a territory. The diagonal lines that connect males WB and BKR in T2 signify that neither bird clearly dominated the other in all aspects of display during July and August. Males that made only one or two visits during an observation period (usually 4 days/month) have been excluded. Initials with an " $i$ " denote an immature male.

species landed either on the main perch or on an adjacent perch while males displayed. In all but one instance, the males continued to display, appearing to ignore the intruder. During visits by larger species $(n=4)$, e.g., motmots and toucans, the resident male sat still and gave Appeasement Whistles until the intruder left the area. In contrast, resident males were quick to respond aggressively to visits by other lekking manakins, i.e., Round-tailed (Pipra chloromeros) or Fiery-capped (Machaeropterus pyrocephalus) manakins. In one case, an immature male Round-tailed Manakin landed on the main perch. The alpha male and another each dived at the immature bird once before one of them chased him from the area. All three times that Fiery-capped Manakins appeared in a territory, they were evicted. Other species apparently were mistaken occasionally for conspecifics, with the resident male initiating display towards the visitor, e.g., the Ochre-bellied Flycatcher (Mionectes oleagi- neus), a species similar in size and coloration to female $P$. fasciicauda.

\section{CHRONOLOGY OF TERRITORY OWNERSHIP}

The stability of relations between alpha and beta males varied considerably among territories (Fig. 1). Territory 1 was the most stable because the alpha (Bl-R) and the beta (BA) males were the same throughout the study. In contrast to the other territories, competition among males for position in the hierarchy was intense in $\mathrm{T} 2$ and $\mathrm{T} 3$ from late June through mid-August. During this period, as many as six adult males made daily visits to $T 2$. With the drastic reduction in available fruit from mid-August through late September, several of the non-territorial males no longer visited T2. From late June through August, WB was the alpha male; however, BKR often dominated display with WB. Of the Swoop-in Flights during the late July period ( $n=4$ days) where both members of a pair were determined, WB 
and BKR performed only one display together. $\mathrm{WB}$ and AA, however, performed $35 \%$ ( $n=$ 134 displays) together, while BKR conducted $20 \%$ with YB. On three of four days, both pairs displayed simultaneously to the same perch within $0.5 \mathrm{~m}$ of each other. During the August period, WB was extremely aggressive; he harassed all other males (particularly AA) by forcing them to move to other perches. BKR and $Y B$ spent most of this period as observers at the north end of the territory. BKR eventually displaced WB as the alpha male and WB was eventually relegated to the non-territorial (visitor) status (Fig. 1). BWB was the alpha male at T3 throughout the study. BY was the beta male at T3 from June through early October; thereafter, RG was the principal displayer with BWB.

Alpha male BW of T4 apparently had difficulty in maintaining an adult male display partner throughout the season, except during September, because most visiting adult males preferred to display in contiguous T2. During July and August, BW made brief daily visits to T2; however, when relations stabilized in T2, BW was no longer tolerated there (Table 1).

The alpha male, RB of T5 during July and August, disappeared in the interval between the August and September observation periods. His former beta male, RW, became the new alpha male, and a former daily visitor, $\mathrm{BG}$, became the new beta male for the remainder of the study.

At T6, the alpha male, BB, abandoned his territory after a felled tree destroyed all the main perches in late August. Subsequently, he became a conspicuous visitor at $\mathrm{T} 2, \mathrm{~T} 3$, and T7 during the remainder of the study. Like the alpha male of T4, the alpha male, RS of T7, apparently had difficulty in maintaining an adult male partner. BA, beta male of $\mathrm{T} 1$, frequently visited and displayed in $\mathrm{T} 7$ during the entire study.

In summary, in four (T1, T3, T4, and T7) out of six territories (excluding the destroyed T6), the alpha male was the same throughout the study, and in those two territories in which a change in dominance position occurred, the alpha male was succeeded by the beta male in its territory (Fig. 1).

\section{DISCUSSION}

The cooperative display among male Bandtailed Manakins represents one of the rarest and most highly derived types of avian mating systems. Given that many piprids were preadapted for the evolution of lek behavior, i.e., a shift in diet from insects to fruit, emancipating males from nesting duties, coupled with the non-defensibility of either food supplies or female groups (see Bradbury 1981 for summary), what factors may have been responsible for the evolution of cooperative display?

If the predecessor of today's cooperativedisplaying piprids had similar behavior to that of the Golden-heacied ( $P$. erythrocephala) and/ or Bearded (Manacus manacus) manakins, then the importance of the reduction or redirection of aggression between males is obvious for joint display to have evolved. One can envision the reduction of aggression between males and, hence, cooperative display preceding as follows (after Foster 1981). Presumably, non-territorial males, as well as females, were attracted to successful, clustered males. Competition among males at a territory may have provided a greater stimulus to visiting females. Thus, territorial males that tolerated other males were selected by females as mates. With female choice of males as a driving force, there continued to be a reduction of aggression between resident and visiting males, thus allowing a system of joint display to develop.

Given this change in aggression levels between males with the evolution of cooperative display, one would expect to find differences in territoriality between cooperative and noncooperative displaying lek species. Although fewer than ten piprids have been studied in any detail, there does appear to be a dichotomy in territoriality between the two groups. Golden-headed and Bearded manakins (non-cooperative displaying species) both show strong intra- and interspecific territoriality. Territorial males of these two species exclude all other male conspecifics, as well as other avian species (Lill 1974, 1976). In contrast, Foster (1981) noted neither intra- (except a dominance hierarchy within a court) nor interspecific territoriality in Chiroxiphia caudata. I saw alpha male $P$. fasciicauda excluding only contiguous territorial owners and other lekking piprids.

It is not surprising that there are pronounced differences in intraspecific territoriality between cooperative and non-cooperative species, in view of the above scenario for the evolution of cooperative display. Clearly, a reduction or re-direction (i.e., agonistic behavior incorporated into non-aggressive, ritualized displays) of aggression between males had to occur as coordinated display evolved. Why there are differences in interspecific territoriality, however, is less clear. Lill (1976) proposed that the interspecific territoriality exhibited by the Golden-headed and Bearded manakins was partially a result of the inherent competitive nature of the lek system. He believed that this appression represents an 
"overflow" from intraspecific territoriality. Unlike the above species, $P$. fasciicauda territories have fruit available throughout most of the breeding season, yet males do not defend this clumped food source. One would expect each owner to exclude other avian species from his food source, unless the energy expended defending it exceeded the energy derived from acquiring it. Most of the mixed-species flocks that made periodic visits contained several species of frugivores. Many of these frugivores weigh, on the average, two or three times more than the male $P$. fasciicauda. Thus, it would appear to be disadvantageous for a male to defend his food source, as the energetic cost of evicting from his territory a dozen or more individuals that are substantially larger in body size than he is would be too great, if not impossible.

Why should $P$. fasciicauda behave territorially toward confamilial species, yet ignore other frugivorous species? Possibly, in this transitional forest, the three lekking manakins, $P$. chloromeros, $P$. fasciicauda, and Machaeropterus, may compete for display sites. Although naturally disturbed areas are not rare in the relatively open, secondary forest, optimal sites, i.e., those with an abundant fruit source and with saplings of the right height with suitable perches for display, may be limited. Presumably, early and late successional stages of a forest clearing may not meet the requirements of lekking manakins. Alternatively, male $P$. fasciicauda may perceive other lekking piprids as rivals competing for females. In general, lekking male manakins are known to be indiscriminate with regard to mating subjects. Male $P$. chloromeros and $\mathrm{Ma}$ chaeropterus may occasionally display to female-plumaged $P$. fasciicauda. Throughout my study, I heard male $P$. chloromeros periodically displaying adjacent to the lek. They were not aggressive toward Greater Manakins (Schiffornis major), a species that is considerably larger than $P$. fasciicauda. Like their congeners, Greater Manakins have relatively dull plumage, the sexes are monomorphic, and the males display solitarily, i.e., males do not form leks. Male $P$. fasciicauda may perceive them as they do other similarly sized species.

Foster (1983) suggested that disruption (interruption of a male's courtship of a female) may have an important influence on the structure of male spacing at leks. She predicted that selection would minimize disruption in one of two ways: (1) the evolution of strict dominance hierarchies among males, or (2) the separation of lek males which may result in the formation of exploded leks.

Foster also summarized the incidence of dis- ruptive behavior in the family Pipridae, and concluded that the genera Pipra and Chiroxiphia fit the predictions, i.e., species with tightly packed territories and a greater number of males/lek show a greater incidence of disruption than do species with more dispersed intermale distance and fewer males/lek.

If disruption has been an important influence in male spacing and number of males/ lek, one should expect to see different rates of disruption between species that have similar social organizations, but different spacing patterns (given equal numbers of males/lek). Both $P$. fasciicauda and $C$. caudata have similar social organizations, i.e., an intraterritorial dominance hierarchy (see above, Foster 1981), but very different interterritorial spacing patterns (tightly packed in $P$. fasciicauda, loosely packed in $C$. caudata). From the above predictions, $P$. fasciicauda should have a greater incidence of disruption than C. caudata (in this comparison, leks of both species had six courts). The disruption rate between $P$. fasciicauda (19.6\%, 10 of 51 encounters) and $C$. caudata $(18.7 \%$, six of 32 encounters; Foster 1981) was not significantly different $\left(\chi^{2}=0.081, \mathrm{df}=1\right.$, $P<0.05)$. In $P$. fasciicauda, all disruptions of a courting male were intraterritorial, i.e., by subordinate males associated with the territory. Apparently, intraterritorial disruption is "frequent" in C. caudata (Foster 1981).

Not only has disruption of courtship in cooperative species appeared to have shifted primarily from interterritorial to intraterritorial, but also the rate of disruption appears to be greater in the above cooperative species than in non-cooperative species that have even more densely packed territories. Disruption in Bearded Manakins was insignificant $(<1 \%$ of all female visits), regardless of the size of the lek (Lill 1974). Male interterritorial invasion during female visits at Golden-headed Manakin leks ranged from ca. $4.5 \%$ (four territorial males) to ca. $8.5 \%$ (16 males), although disruption of copulation ranged from ca. $4 \%$ to $26 \%$ at the same leks (Lill 1976). Moreover, disruption is unrecorded for the non-cooperative displaying Blue-crowned (Pipra coronata) and Red-capped (Pipra mentalis) manakins; male interterritorial distances for both species are intermediate between those for $P$. fasciicauda and C. caudata (Skutch 1949, 1969). From the above comparisons, there appears to be little correlation between disruption rates and male spacing at piprid leks.

The chronology data offer insights into the acquisition of territories at $P$. fasciicauda leks. Within a single field season, I observed a $33.3 \%$ (two of six males; one lek) turnover in alpha males. In both instances, the former beta male 
became the new alpha male. Acquisition of the alpha position, however, was very different in these two cases. In the first case, the beta male inherited the alpha position after the alpha male disappeared between observation periods. At the other territory, the beta male usurped the alpha male, with the two exchanging positions within the hierarchy. Shortly after the reversal, the new alpha male copulated with a female, while the former alpha male watched from an adjacent perch.

Evidently, prior ownership of a territory has little influence on obtaining a position (alpha or beta) at another territory at the same lek within a season. In the above case where the alpha male was usurped, he was eventually relegated to the non-territorial position and did not obtain a position at any other territory. Likewise, the alpha male that had his territory destroyed by a felled tree never became established at another territory, even though he competed and displayed daily at other territories within the lek. A long-term study of this species is needed to determine if males maintain their status and territories over years.

\section{ACKNOWLEDGMENTS}

I am most grateful to J. V. Remsen, Jr., for guidance and comments on various drafts of this manuscript. I thank J. P. O'Neill for assistance throughout the study. M. C. Gunther and Peruvian Safaris deserve special thanks for providing food and lodging at the Tambopata Natural Reserve (Explorer's Inn). Comments from M. S. Foster, S. M. Lanyon, and M. F. Lawton also benefited the manuscript. T. A. Parker, III, and S. Allen provided information about the Tambopata Reserve and previously banded manakins. My wife provided encouragement throughout the study. I thank the Direccion General Forestal y de Fauna, Lima, for authorization of and interest in my fieldwork in Peru. My fieldwork in Peru was supported by B. M. Odom, J. S. McIlhenny, L. Schweppe, I. Schweppe, and the Louisiana State University Museum of Zoology.
I gratefully acknowledge the support of these people and institutions.

\section{LITERATURE CITED}

BradBURY, J. W. 1981. Evolution of leks, p. 138-169. In R. D. Alexander and D. Tinkle [eds.], Natural selection of social behavior. Chiron, NY.

Foster, M. S. 1977. Odd couples in manakins; a study of social organization and cooperative breeding in Chiroxiphia linearis. Am. Nat. 111:845-853.

Foster, M. S. 1981. Cooperative behavior and social organization of the Swallow-tailed Manakin (Chiroxiphia caudata). Behav. Ecol. Sociobiol. 9:167-177.

Foster, M. S. 1983. Disruption, dispersion, and dominance in lek-breeding birds. Am. Nat. 122:53-72.

Gilliard, E. T. 1959. Notes on the courtship behavior of the Blue-backed Manakin (Chiroxiphia pareola). Am. Mus. Novit. No. 1942.

LILL, A. 1974. Social organization and space utilization in the lek-forming White-bearded Manakin (M. manacus trinitalis Hartert). Z. Tierpsychol. 36:513-530.

LILL, A. 1976. Lek behavior in the Golden-headed Manakin, Pipra erythrocephala, in Trinidad (West Indies). Z. Tierpsychol. Suppl. 18.

Oficina Nacional de Evaluacion de Recursos NaturALES. 1976. Mapa ecologico del Peru. Guia explicativa. Lima, Peru.

RobBins, M. B. 1983. The display repertoire of the Bandtailed Manakin (Pipra fasciicauda). Wilson Bull. 95: 321-342.

SChwartz, P., AND D. W. SNow. 1978. Display and related behavior of the Wire-tailed Manakin. Living Bird 17:51-78.

SICK, H. 1967. Courtship behavior in the manakins (Pipridae). Living Bird 6:5-22.

SKuTCH, A. F. 1949. Life history of the Yellow-thighed Manakin. Auk 66:1-24.

SkUTCH, A. F. 1969. Life histories of Central American birds. III. Pacific Coast Avifauna No. 35.

SLud, P. 1957. The song and dance of the Long-tailed Manakin, Chiroxiphia linearis. Auk 74:333-339.

SNow, D. W. 1963. The evolution of manakin displays. Proc. XIII Int. Ornithol. Congr. (1962):553-561.

Museum of Natural Sciences, Louisiana State University, Baton Rouge, Louisiana 70893. Present address: Academy of Natural Sciences, 19th and The Parkway, Philadelphia, $P A$ 19103. Received 25 July 1983 . Final acceptance 30 May 1985. 